\title{
Research as a Deliberate Chess Activity Software Testing Platform for Professional Dynamic Development of the Education Sector
}

\author{
Ruben Mirzakhanyan, Srbuhi Gevorgyan, Vladimir Karapetyan \\ Armenian State Pedagogical University Named After Khachatur Abovyan, Yervan, Armenia
}

\begin{abstract}
Current paper presents the influence of academic chess activity in Armenian schools. Nowadays, people face many obstacles connected with the high quality education. This sphere forces them to implement new methods and approaches in everyday learning process. The following academic research done on research as a deliberate chess activity software testing platform for professional dynamic development of the education sector showed that the implementation of academic chess with low grade students may have positive effect. The experiment done in this paper is closely related to the inclusive education as well. Mainly this experiment showed that collaborative training or learning can be very positive when children with disabilities are integrated in the learning process.
\end{abstract}

Keywords: academic chess, chess at schools, achievements of students

\section{Introduction}

In Armenia, further development of chess activity and its strategic importance is directly related to the fact of understanding and assessment that the population (especially young families) what is the perception of chess which can strengthen its role in the education of the rising generation. Sociological and psychological studies in terms of identifying the role of chess in society showed that positive social environment has an impact on the purposeful communication technologies, teaching and learning materials for pupils of perception, and understanding and mastering the basic processes. The impact on motivating educational environment for pupils can have a positive impact not only on academic performance but also on the development of the friendly and intimate relationship, with the help of which educational environment in fact can be turned into an educational location.

\footnotetext{
Ruben Mirzakhanyan, Ph.D. in historical sciences, professor, Armenian State Pedagogical University named after Khachatur Abovyan, Yervan, Armenia.

Srbuhi Gevorgyan, Ph.D. in psychology, professor, Armenian State Pedagogical University named after Khachatur Abovyan, Yervan, Armenia.

Vladimir Karapetyan, Ph.D. in psychology, professor, Armenian State Pedagogical University named after Khachatur Abovyan, Yervan, Armenia.

Correspondence concerning this article should be addressed to Srbuhi Gevorgyan, Armenian State Pedagogical University named after Khachatur Abovyan, House 15, Street Komitas, Yervan, Armenia.
} 


\section{Literature Review}

\section{Motivation of Chess Activity}

In the scientific terminology, the ambiguous definition of term "motivation" has serious controversy regarding the interpretation and application of the term, as "motive" includes in it content, such as "demand", "push", "tend", "seek", etc. Authors put any undue expansion of the scope of the concept of continually leaving negative effect on the motivation associated with the expansion of the meaning. Of course, the same reasoning applies to the activities of chess playing motivations also for studying and resolving identified problems (Ferguson, 1986). However, there are various definitions and concepts of motivation that authors tried to work through a targeted manner and separate basic concepts of it, so that on one side it should not be inconsistent with the already accepted idea, on the other hand other professionals of the industry should accept motive as the enforcement or implementation of procedural functions. In this sense, authors tried to discern the motivation of chess activity with the motivation of chess education. So the chess activity motivation is being considered as an educational goal-oriented motive for such a system, which includes components including: (a) a guideline chess ground; (b) actions (chess moves) the method or methods (alternative case) selection; (c) continuous monitoring of teacher performance not only in chess, but especially the child; and (d) the results of the interim and final evaluation of chess activity operators. According to Leonhard and Krasnova (2010), educational motive as the main component of chess activity, beside its stand-alone content and commentary, during the chess actions, in terms of function and structure, has some psychological potential, because otherwise the existence or educational motive does not become concrete, it would be considered as actions towards chess activity or close action to its expression. Students' academic performance towards chess frequently occurs on repeated action, here on the analysis of causal relations can be viewed as a joint training, if children are taught in jointly organized not only expected, but also cooperative activities mandatory within the concept of individual learning activities, especially, meaning that it is relevant in so far as it enables children to interact with each other during classes, clarify this or that idea or process to understand and learn, as well as his classmates in a social activity. "Peers for peers through peer" is the motto of the simplest scheme of learning, collaborating, especially across the same interests in the field of inclusive education, and teaching chess organization.

\section{The Essence of Loaded Chess Activity Motivation}

Collaborative activities were organized during chess lessons based on the children's academic performance or educational standards, also with received low, medium, or high scores according to the Armenian educational standards. According to Resolution of the Government of the Russian Federation (2011), various academic performances connected with the (low, average, and high) grades of the same classroom pupils showed that in accordance of subjects with the same educational motive, it helps children to have better performance. Here it is obvious that their performance is high for the chess and math grade performance. Although the motive mostly shows the specific action or actions, nevertheless, the nature of mental or physical actions (according to form) really is not so important in terms of interpreting the results of chess activity.

\section{Research Methods}

Motivation dominant action ideas can be divided into four parts at least: (1) understanding of chess, the 
motives, and the system as a reference system based on information; (2) operating and financial performance of the system included the dominant activity (exercise), such as capability; (3) motivation load operation by baby monitors; and (4) current performance evaluation and final decision. Therefore, based on the resuts of Chess Academy of Armenia, Armenian State Pedagogical University named after Khachaur Abovyan University and its chess experimental research center, also based on the interantional scinetific conference Chess in Schools 2014, it showed that there was a need to examine the middle school students' motivation towards learning, also to find out what exactly pushes two to four grades to practice chess and what was the main interest.

\section{The Empirical Experiment of Motivation With Its Component}

Below there is a questionnaire, which was built exclusively based on interviews held with chess teachers and schoolchildren. Questions were quite simple and specific, but the answers were accepted when the chess teacher knew the pupil at least for one academic year. Since 2011, of two to four grades in all schools in the Republic of Armenia, chess is taught as a compulsory subject of study.

In fact, chess teachers were able at least for a year (before specific day of answering to the questions) to have a diary to record the grades and achievements of students' motivation system towards chess.

\section{Research Results}

\section{Motivation Components (Descriptive Sense)}

(1) Schoolchildren are ready for more extra chess lessons if it is absolutely necessary:

$$
(\text { ratio } 0.46)^{4}
$$

(2) Interested in successful execution of the whole chess task and not only a specific section:

(ratio 0.40)

(3) Give all energy and investment in the exams and try to set specific issues of chess tasks:

(ratio 0.36)

(4) During free time or when they have free time, actively looking for a chess-related information:

$$
\text { (ratio 0.31) }
$$

(5) Very often they search above the norm for more information of the chess tasks:

$$
\text { (ratio 0.36) }
$$

(6) Always interested in chess activity task life:

(ratio 0.31)

(7) Search for chess task news and information more than they need for regular required lessons:

(ratio 0.29)

(8) Continue to search chess task news until they find something interesting and useful:

$$
\text { (ratio 0.28) }
$$

(9) Finish chess-related work completely without any significant gaps:

(ratio 0.27) 


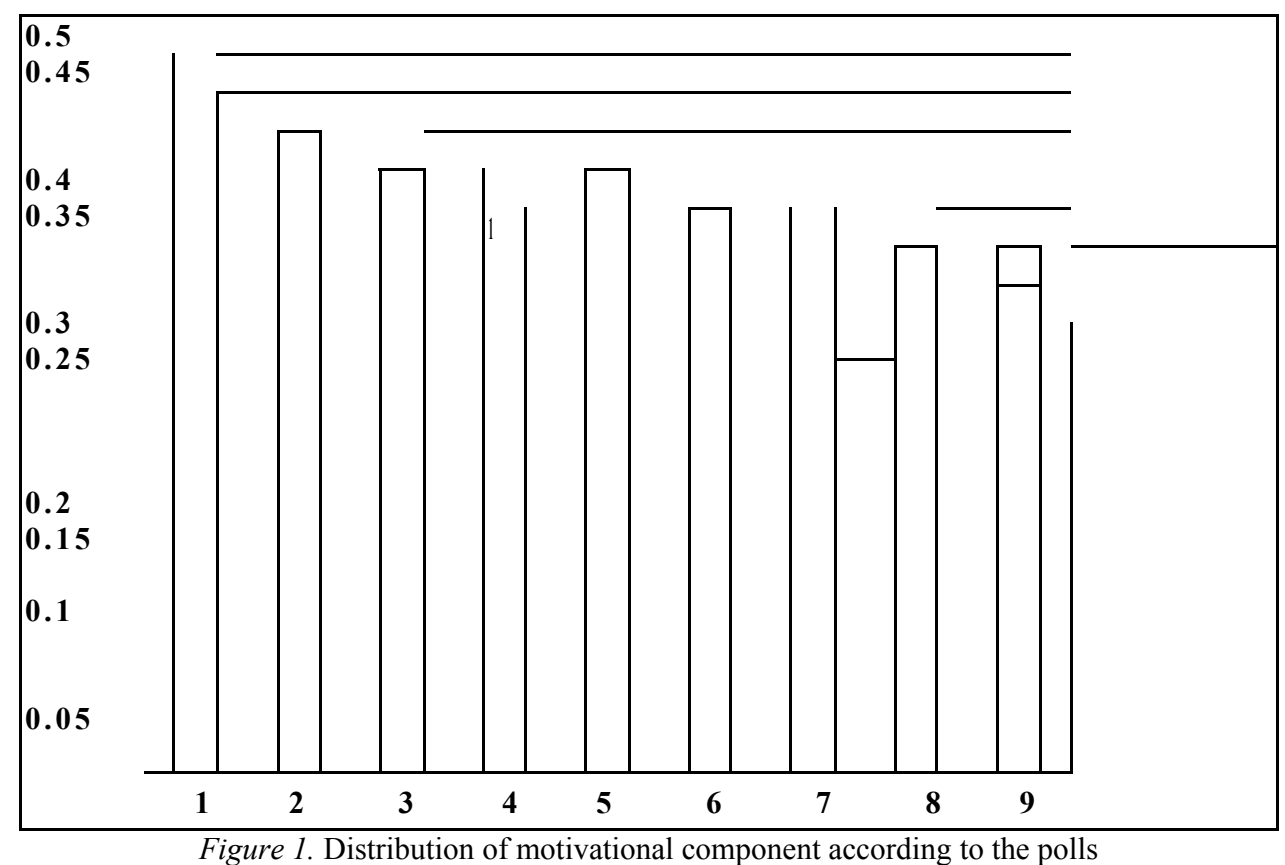

The weights are determined solely on the results of the surveys of participants; they are based on the actual number of participants rather than on the importance of judgment (Figure 1).

Now for the results of the questionnaire addressed to the chess teachers, below there is a questionnaire of responses (Figure 2).

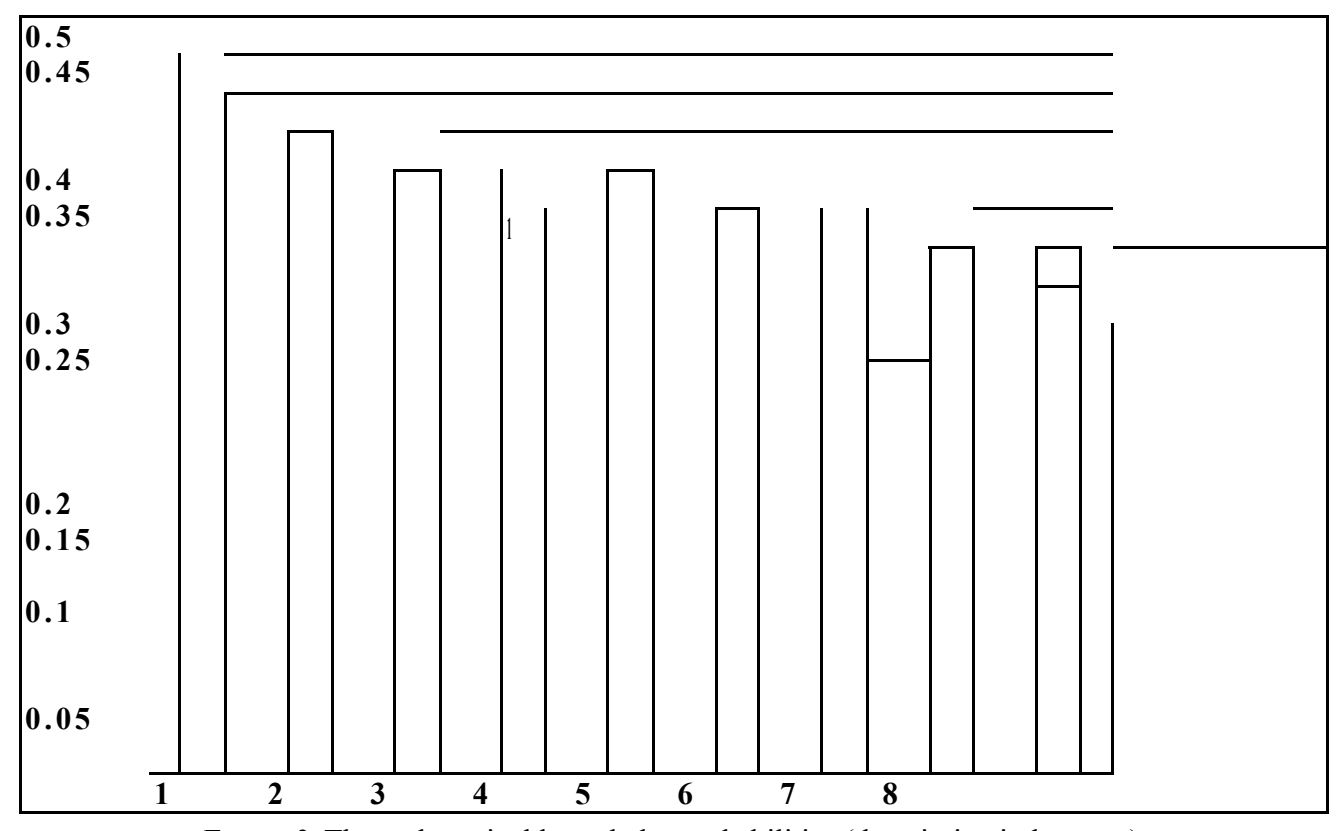

Figure 2. The pedagogical knowledge and abilities (descriptive judgments).

- Often chess teacher has the necessary knowledge to help other chess partners to solve problems of the pedagogical nature (ratio 0.38);

- It knows the basic principles, professional chess players' knowledge, and approaches (ratio 0.28); 
- Colleagues ask questions concerning chess teaching issues in the classrooms (ratio 0.35);

- Most of the time was spent on collecting necessary information about the life of chess and on reading subject journals (ratio 0.31);

- Before accepting an offer connected with chess which requires the pedagogical nature, it needs pedagogical and psychological justifications (weight 0.29);

- His/her pedagogical ideas are applicable to chess lessons and they are quite literate (ratio 0.28);

- Very often applies his/ her theoretical knowledge (ratio 24);

- During any obstacles, it is able to use alternative ways of seeking solutions (ratio 0.24);

- It is able to divide the required number of relatively complex issues into simple parts, in order to find "substantive" solutions (ratio 0.19).

\section{Analysis and Discussion}

The experiments convinced that in inclusive educational system, the formation of different kind of social conditions requires the creation of such social conditions which will ensure not competition but cooperation. That is to say that children with better academic performance will equally discuss the operational implementation of the action with children with disabilities. In the beginning, children were asked who will wish to cooperate during class with impaired development (to chat, to explain, etc.). Firstly, a large number of applicants were not willing, but when they realized that they had to replace temporarily their teachers, many of them were motivated and even glad that they are "teachers" or "teacher assistants". Collaborative groups were formed randomly. During the experiment, the main thing was to find out that children with disabilities could answer the questions in collaborative groups, for that reason, each child was working with two other normally developed children.

They had to give additional explanations in a low voice along with the teacher's talk for children with disabilities, further they explained the teacher's comments and answers. Sometimes, this process was carried out outside of classes. If the teacher asked the question, the correct responses were two out of three given by the normally developed children and only one correct answer was given by the included child. It was praised when any of the children involved in the experiment expressed desire to answer the teacher's questions. Teachers tried to motivate and integrate them in the learning process. The final data and results are presented in Table 1.

Table 1

Numbers of Cooperative Learning, Control of Average Responses

\begin{tabular}{lllll}
\hline Classes & $\begin{array}{l}\text { The number of included } \\
\text { children according to the } \\
\text { classrooms }\end{array}$ & $\begin{array}{l}\text { Responses for the } \\
\text { three questions correctly } \\
\text { answered questions } \\
\text { (average numbers per } \\
\text { included child) }\end{array}$ & $\begin{array}{l}\text { The number responses of } \\
\text { normally developed } \\
\text { children }\end{array}$ & $\begin{array}{l}\text { Correct responses } \\
\text { for three questions } \\
\text { (average numbers per } \\
\text { normally developed child) }\end{array}$ \\
\hline 3rd grade & 3 & 14 & 6 & 15 \\
4th grade & 3 & 13 & 7 & 14 \\
5th grade & 4 & 13 & 8 & 15 \\
6th grade & 4 & 10 & 8 & 13 \\
\hline
\end{tabular}

Apparently, the number of correct answers were about same comparing the responses of normally developed and included children. This experiment showed that collaborative training or learning can be very positive when children with disabilities are integrated in the learning process. Some of the children said that 
their classmates were helping them with responses. Naturally, the question arises here- the possibility of correct responses without the help of classmates. Below you can see the results of the control group (Table 2).

Table 2

The Averaged Responses to the Key Questions

\begin{tabular}{lllll}
\hline Classes & $\begin{array}{l}\text { The number of included } \\
\text { children according to the } \\
\text { classrooms }\end{array}$ & $\begin{array}{l}15 \text { answers to the key } \\
\text { questions } \\
\text { (average numbers per } \\
\text { included child) }\end{array}$ & $\begin{array}{l}\text { The number responses } \\
\text { given by the of normally } \\
\text { developed children }\end{array}$ & $\begin{array}{l}15 \text { answers to the key } \\
\text { questions } \\
\text { (average numbers per } \\
\text { included child) }\end{array}$ \\
\hline 3rd grade & 3 & 9 & 6 & 13 \\
4th grade & 3 & 8 & 7 & 12 \\
5th grade & 4 & 8 & 8 & 10 \\
6th grade & 4 & 7 & 8 & 11 \\
\hline
\end{tabular}

It turned out that the number of correct responses decreased both with the normally developed and included children. Many observations and analysis revealed that the change of self-valuation of children with disabilities is connected with locus of control. Children with disabilities did not understand most of the questions, and they stressed majority of the given questions and gave wrong responses. Also it is worth to mention that there has been a decrease in attention, so the responses were not correct. However, the experiment showed that the academic achievements may help children with disabilities to increase their self-valuation and confidence.

\section{Conclusions}

One of the main purposes of the current study is to investigate further development of chess activity and its strategic importance. The fact of understanding the perception of an academic chess can strengthen its role in the education of the rising generation. Sociological and psychological studies in terms of identifying the role of chess in society showed that positive social environment has an impact on the purposeful communication technologies, teaching and learning materials for pupils of perception, and understanding and mastering the basic processes. The study was carried out at the Armenian State Pedagogical University named after Khachaur Abovyan and its chess experimental research center, also based on the interantional scinetific conference Chess in Schools 2014. Firstly, a large number of applicants were not willing but when they realized that they had to replace temporarily their teachers, many of them with performance will equally discuss the operational implementation of the action with children with disabilities. In the beginning, children were asked who will wish to cooperate during class with impaired development (to chat, to explain, etc.). That is to say that children with better academic performance will equally discuss the operational implementation of the action with children with disabilities.

\section{References}

Leonhard, E. I., \& Krasnova, N. A. (2010). Inclusive education in different conditions of an integration (Moscow State University of Psychology and Education, pp. 139-148).

Ferguson, R. (1986). Developing critical and creative thinking through chess (Report on ESEA Title IV-C project presented at the annual conference of the Pennsylvania Association for Gifted Education, Pittsburgh, Pennsylvania).

Resolution of the Government of the Russian Federation. (2011). Federal target program of educational development for 2011-2015. Higher education in Russia in the twenty-first century: Searching for excellence (World Studies in Education). 